\title{
On almost contractions in partially ordered metric spaces via implicit relations
}

Uğur Gül ${ }^{1 *}$ and Erdal Karapınar ${ }^{2}$

${ }^{\text {*Correspondence: }}$ gulugur@gmail.com

'Department of Mathematics, Hacettepe University, Ankara, Turkey Full list of author information is available at the end of the article

\begin{abstract}
In this paper, we prove general fixed point theorems for self-maps of a partially ordered complete metric space which satisfy an implicit type relation. Our method relies on constructive arguments involving Picard type iteration processes and our uniqueness result uses comparability arguments. Our results generalize a multitude of fixed point theorems in the literature to the context of partially ordered metric spaces.
\end{abstract}

\section{Introduction}

Fixed point theorems in nonlinear analysis have become indispensable tools in a vast area of the analysis ranging from proving the existence of solutions of certain partial differential equations to nonlinear optimization and related fields (see, for instance, [1]). Having their origin in the classical paper of Stefan Banach [2] as the 'Banach Contraction Mapping Theorem' (which is by now so classical that it appears in almost every book on Functional Analysis), fixed point theorems have attracted a lot of attention during the past five decades. This is mainly due to the fact that they have found many applications to the problems in applied mathematics such as boundary value problems in differential equations. The 'Banach Contraction Mapping Theorem' was generalized by many authors to mappings that satisfy much weaker conditions (see, for instance, [3-10]). Banach's theorem was also extended to mappings which have an invariant subset that is finite, namely that have 'periodic points' [11, 12]. Another direction where the theorem was extended is for more than one mapping which have common fixed points [13-15]. In recent years, Banach's theorem was extended in part to partially ordered metric spaces by Ran and Reuring [16] in order to obtain a solution of a matrix equation. Nieto and López [17] generalized the result of Ran and Reuring by removing the continuity condition of the mapping. They applied their result to get a solution of a boundary value problem. The efficiency of these kind of extensions of fixed point theorems in such kind of problems, as it is well known, is due to the fact that most real valued function spaces are partially ordered metric spaces.

Alber and Guerre-Delabriere [18] introduced the notion of weak $\phi$-contraction: A selfmapping $T$ on a metric space $X$ is called weak $\phi$-contraction if $\phi:[0, \infty) \rightarrow[0, \infty)$ is a strictly increasing map with $\phi(0)=0$ and

$$
d(T x, T y) \leq d(x, y)-\phi(d(x, y)) \quad \text { for all } x, y \in X
$$

In fact, it is a generalization of $\Phi$-contraction, introduced by Boyd and Wong [19]: A self-mapping $T$ on a metric space $X$ is called $\Phi$-contraction if there exists an upper semi-

\section{至 Springer}

C 2012 Gül and Karapınar; licensee Springer. This is an Open Access article distributed under the terms of the Creative Commons Attribution License (http://creativecommons.org/licenses/by/2.0), which permits unrestricted use, distribution, and reproduction in any medium, provided the original work is properly cited. 
continuous function $\Phi:[0, \infty) \rightarrow[0, \infty)$ such that

$$
d(T x, T y) \leq \Phi(d(x, y)) \quad \text { for all } x, y \in X .
$$

We underline that for a lower semi-continuous mapping $\phi$, the function $\Phi(u)=u-$ $\phi(u)$ coincides with Boyd and Wong types. These two notions, $\Phi$-contraction and weak $\phi$-contraction, have been studied heavily by many authors in fixed point theory (see, e.g., [20-30]).

Our aim in this paper is to obtain fixed point theorems for mappings acting on partially ordered complete metric spaces which satisfy certain implicit relations. There are indeed fixed point theorems for mappings satisfying such kind of relation in the literature; however, all of these fixed point theorems are on complete metric spaces that are not partially ordered spaces. The novelty of this work lies in generalizing these fixed point theorems to partially ordered spaces.

Throughout this paper, $(X, d, \preceq)$ denotes a partially ordered metric space where $(X, \preceq)$ is a partially ordered set and $(X, d)$ is a metric space for a given metric $d$ on $X$. A partially ordered metric space $(X, d, \preceq)$ is called regular, if for each convergent sequence $\left\{x_{n}\right\}_{n=0}^{\infty} \subset$ $X$, the following condition holds: either

- if $\left\{x_{n}\right\}$ is a non-increasing sequence in $X$ such that $x_{n} \rightarrow x^{*}$ implies $x^{*} \preceq x_{n} \forall n \in \mathbb{N}$,

or

- if $\left\{x_{n}\right\}$ is a non-decreasing sequence in $X$ such that $x_{n} \rightarrow x^{*}$ implies $x_{n} \preceq x^{*} \forall n \in \mathbb{N}$.

Let $\Phi$ be the class of all strictly increasing lower semi-continuous functions $\phi:[0, \infty) \rightarrow$ $[0, \infty)$ with $\phi(0)=0$. Let $\mathbb{F}$ denote the class of all implicit continuous functions $F$ : $\left(\mathbb{R}^{+}\right)^{6} \rightarrow \mathbb{R}$. We shall consider the following subclasses of $\mathbb{F}$ :

$\left(\mathbb{F}_{1}\right) \quad F \in \mathbb{F}$ is non-increasing in the fifth variable, and $F(u, v, v, u, u+v, 0) \leq 0$ for $u, v>0$ implies that there exists a function $\phi \in \Phi$ such that $u \leq v-\phi(v)$.

$\left(\mathbb{F}_{2}\right) F \in \mathbb{F}$ is non-increasing in the fifth variable, and $F(u, v, v, u, u+v, 0) \leq 0$ for $u, v>0 \Longrightarrow$ $\exists k \in[0,1)$ such that $u \leq k v$.

$\left(\mathbb{F}_{3}\right) F \in \mathbb{F}$ is non-increasing in the fourth variable, and $F(u, v, 0, u+v, u, v) \leq 0$ for $u, v>$ $0 \Longrightarrow \exists k \in[0,1)$ such that $u \leq k v$.

$\left(\mathbb{F}_{4}\right) F \in \mathbb{F}$ is non-increasing in the third variable, and $F(u, v, u+v, 0, v, u) \leq 0$ for $u, v>$ $0 \Longrightarrow \exists k \in[0,1)$ such that $u \leq k v$.

$\left(\mathbb{F}_{5}\right) F \in \mathbb{F}$ such that $F(u, u, 0,0, u, u)>0$ for all $u>0$.

See [31,32] for examples of functions $F \in \mathbb{F}$ satisfying the above conditions $\mathbb{F}_{1}-\mathbb{F}_{5}$.

\section{Main results}

We start this section with the first main result.

Theorem 1 Let $(X, d, \preceq)$ be a partially ordered metric space which is complete. Assume that $T: X \rightarrow X$ is a continuous map satisfying $x \preceq T x \forall x \in X$, and let $T$ satisfy

$$
F(d(T x, T y), d(x, y), d(x, T x), d(y, T y), d(x, T y), d(y, T x)) \leq 0 \quad \text { for all } x \geq y,
$$

where $F \in \mathbb{F}_{1} \cap \mathbb{F}_{5}$. Then $T$ has a fixed point. 
Proof Let $x_{0} \in X$ be arbitrary. Since $T$ is non-decreasing, we have $x_{0} \preceq T x_{0}$. We define a sequence $\left\{x_{n}\right\}$ in $X$ as follows:

$$
x_{n}=T x_{n-1} \quad \text { for } n \geq 1 \text {. }
$$

Considering that $T$ is a non-decreasing mapping together with (2.2), we have $x_{2}=T x_{1} \succeq x_{1}$. Inductively, we obtain

$$
x_{0} \preceq x_{1} \preceq x_{2} \preceq \cdots \preceq x_{n-1} \preceq x_{n} \preceq x_{n+1} \preceq \cdots .
$$

Assume that there exists $n_{0}$ such that $x_{n_{0}}=x_{n_{0}+1}$. Since $x_{n_{0}}=x_{n_{0}+1}=T x_{n_{0}}$, then $T$ has a fixed point which ends the proof. Suppose that $x_{n} \neq x_{n+1}$ for all $n \in \mathbb{N}$. Thus, by (2.3), we have

$$
x_{0} \prec x_{1} \prec x_{2} \prec \cdots \prec x_{n-1} \prec x_{n} \prec x_{n+1} \prec \cdots
$$

Taking (2.1) into account, we derive that

$$
F\left(d\left(x_{n}, T x_{n}\right), d\left(x_{n-1}, x_{n}\right), d\left(x_{n-1}, x_{n}\right), d\left(x_{n}, x_{n+1}\right), d\left(x_{n-1}, x_{n+1}\right), 0\right) \leq 0 .
$$

By the triangle inequality, we have

$$
d\left(x_{n-1}, x_{n+1}\right) \leq d\left(x_{n}, x_{n+1}\right)+d\left(x_{n-1}, x_{n}\right) .
$$

Since $F$ is non-increasing in the fifth variable, the inequality (2.5) turns into

$$
F\left(d\left(x_{n}, T x_{n}\right), d\left(x_{n-1}, x_{n}\right), d\left(x_{n-1}, x_{n}\right), d\left(x_{n}, x_{n+1}\right), d\left(x_{n}, x_{n+1}\right)+d\left(x_{n-1}, x_{n}\right), 0\right) \leq 0,
$$

and by using the property of $\mathbb{F}_{1}$, there exists a function $\phi \in \Phi$ such that

$$
\begin{aligned}
d\left(x_{n}, x_{n+1}\right) & \leq d\left(x_{n}, x_{n-1}\right)-\phi\left(d\left(x_{n}, x_{n-1}\right)\right) \\
& \leq d\left(x_{n}, x_{n-1}\right),
\end{aligned}
$$

which implies that $\left\{d\left(x_{n}, x_{n+1}\right)\right\}_{n=0}^{\infty}$ is a non-increasing sequence of positive numbers. Hence, there exists $L \geq 0$ such that

$$
\lim _{n \rightarrow \infty} d\left(x_{n}, x_{n+1}\right)=L
$$

We shall show that $L=0$. Suppose, on the contrary, that $L>0$. Since $\phi$ is a lower semicontinuous function, we have

$$
\phi(L) \leq \liminf _{n \rightarrow \infty} \phi\left(d\left(x_{n}, x_{n+1}\right)\right) .
$$

Letting $n \rightarrow \infty$ in (2.6), we derive that

$$
L \leq L-\liminf _{n \rightarrow \infty} d\left(x_{n}, x_{n+1}\right) \leq L-\phi(L)
$$


which is possible only if $\phi(L)=0$. It is a contradiction. Hence $L=0$, that is,

$$
\lim _{n \rightarrow \infty} d\left(x_{n}, x_{n+1}\right)=0
$$

We shall show that $\left\{x_{n}\right\}$ is a Cauchy sequence. Suppose, to the contrary, that $\left\{x_{n}\right\}$ is not a Cauchy sequence. This means that there also exists $\varepsilon>0$ for which we can find subsequence $\left\{x_{n(k)}\right\},\left\{x_{m(k)}\right\}$ of $\left\{x_{n}\right\}$ with $n(k)>m(k)>k$ such that

$$
d\left(x_{n(k)}, x_{m(k)}\right) \geq \varepsilon
$$

We can choose $n(k)$ corresponding to $m(k)$ in a way that it is the smallest integer with $n(k)>m(k)>k$ such that

$$
d\left(x_{n(k)-1}, x_{m(k)}\right)<\varepsilon .
$$

By using the triangle inequality together with (2.11),

$$
\begin{aligned}
d\left(x_{n(k)}, x_{m(k)}\right) & \leq d\left(x_{n(k)}, x_{n(k)-1}\right)+d\left(x_{n(k)-1}, x_{m(k)}\right) \\
& \leq d\left(x_{n(k)}, x_{n(k)-1}\right)+\varepsilon .
\end{aligned}
$$

Combining (2.12) and (2.10),

$$
\varepsilon \leq d\left(x_{n(k)}, x_{n(k)-1}\right)+\varepsilon
$$

Letting $k \rightarrow \infty$ in the inequality above together with (2.9), we derive that

$$
\begin{aligned}
& \lim _{k \rightarrow \infty} d\left(x_{n(k)}, x_{m(k)}\right)=\varepsilon, \\
& \varepsilon \leq d\left(x_{n(k)}, x_{m(k)}\right) \leq d\left(x_{n(k)}, x_{n(k)-1}\right)+d\left(x_{n(k)-1}, x_{m(k)-1}\right)+d\left(x_{m(k)-1}, x_{m(k)}\right), \\
& d\left(x_{n(k)-1}, x_{m(k)-1}\right) \leq d\left(x_{n(k)}, x_{n(k)-1}\right)+d\left(x_{n(k)}, x_{m(k)}\right)+d\left(x_{m(k)-1}, x_{m(k)}\right) .
\end{aligned}
$$

Combining (2.14) and (2.15), we get

$$
\begin{aligned}
\varepsilon-d\left(x_{n(k)}, x_{n(k)-1}\right)-d\left(x_{m(k)-1}, x_{m(k)}\right) \leq & d\left(x_{n(k)-1}, x_{m(k)-1}\right) \\
\leq & d\left(x_{n(k)}, x_{n(k)-1}\right)+d\left(x_{n(k)}, x_{m(k)}\right) \\
& +d\left(x_{m(k)-1}, x_{m(k)}\right) .
\end{aligned}
$$

Letting $k \rightarrow \infty$ in (2.16) together with (2.9) and (2.13), we find that

$$
\lim _{k \rightarrow \infty} d\left(x_{n(k)-1}, x_{m(k)-1}\right)=\varepsilon
$$

On the other hand, by using the triangle inequality,

$$
d\left(x_{n(k)-1}, x_{m(k)-1}\right) \leq d\left(x_{n(k)}, x_{n(k)-1}\right)+d\left(x_{n(k)}, x_{m(k)-1}\right),
$$


which yields that

$$
d\left(x_{n(k)-1}, x_{m(k)-1}\right)-d\left(x_{n(k)}, x_{n(k)-1}\right) \leq d\left(x_{n(k)}, x_{m(k)-1}\right)<\varepsilon .
$$

Letting $k \rightarrow \infty$ in (2.19) together with (2.9) and (2.17), we obtain that

$$
\lim _{k \rightarrow \infty} d\left(x_{n(k)-1}, x_{m(k)}\right)=\varepsilon
$$

Analogously, we have

$$
\lim _{k \rightarrow \infty} d\left(x_{n(k)}, x_{m(k)-1}\right)=\varepsilon .
$$

Since (2.3), we get

$$
F\left(\begin{array}{l}
d\left(T x_{n(k)-1}, T x_{m(k)-1}\right), d\left(x_{n(k)-1}, x_{m(k)-1}\right), d\left(x_{n(k)-1}, T x_{n(k)-1}\right), \\
d\left(x_{m(k)-1}, T x_{m(k)-1}\right), d\left(x_{n(k)-1}, T x_{m(k)-1}\right), d\left(x_{m(k)-1}, T x_{n(k)-1}\right)
\end{array}\right) \leq 0,
$$

which is equivalent to

$$
F\left(\begin{array}{l}
d\left(x_{n(k)}, x_{m(k)}\right), d\left(x_{n(k)-1}, x_{m(k)-1}\right), d\left(x_{n(k)-1}, x_{n(k)}\right), \\
d\left(x_{m(k)-1}, x_{m(k)}\right), d\left(x_{n(k)-1}, x_{m(k)}\right), d\left(x_{m(k)-1}, x_{n(k)}\right)
\end{array}\right) \leq 0 .
$$

By continuity of $F$, letting $k \rightarrow \infty$ in (2.22), we get

$$
F(\varepsilon, \varepsilon, 0,0, \varepsilon, \varepsilon) \leq 0
$$

which contradicts $\mathbb{F}_{5}$. Hence, $\left\{x_{n}\right\}$ is a Cauchy sequence. Since $X$ is a complete metric space, we have $\lim x_{n}=x^{*} \in X$. Since $T$ is continuous,

$$
x^{*}=\lim _{n \rightarrow \infty} x_{n+1}=\lim _{n \rightarrow \infty} T x_{n}=T\left(\lim _{n \rightarrow \infty} x_{n}\right)=T x^{*} .
$$

We remove the continuity condition of the mapping $T$ in Theorem 1 by replacing the condition that $X$ is regular.

Theorem 2 Let $(X, d, \preceq)$ be a partially ordered metric space which is complete and regular. Assume that $T: X \rightarrow X$ is a non-decreasing map, and let $T$ satisfy

$$
F(d(T x, T y), d(x, y), d(x, T x), d(y, T y), d(x, T y), d(y, T x)) \leq 0 \quad \text { for all } x \succeq y,
$$

where $F \in \mathbb{F}_{1} \cap \mathbb{F}_{5}$. Then $T$ has a fixed point.

Proof Following the line in the proof of Theorem 1, we get a Cauchy sequence $\left\{x_{n}\right\}$ as it is defined above. Since $X$ is a complete metric space, we have $\lim x_{n}=x^{*} \in X$. Since $(X, d)$ is regular, we have $x^{*} \preceq x_{n} \forall n \in \mathbb{N}$.

Hence, taking $x:=x_{n}$ and $y:=x^{*}$ in equation (2.24), we have

$$
F\left(d\left(T x_{n}, T x^{*}\right), d\left(x_{n}, x^{*}\right), d\left(x_{n}, T x_{n}\right), d\left(x^{*}, T x^{*}\right), d\left(x_{n}, T x^{*}\right), d\left(x^{*}, T x_{n}\right)\right) \leq 0
$$


for all $n \in \mathbb{N}$. Since $F$ is continuous, letting $n \rightarrow \infty$, we have

$$
F\left(d\left(x^{*}, T x^{*}\right), 0,0, d\left(x^{*}, T x^{*}\right), d\left(x^{*}, T x^{*}\right), 0\right) \leq 0 .
$$

Hence, by $\mathbb{F}_{5}$, we have $d\left(x^{*}, T x^{*}\right) \leq 0$, which implies that $x^{*}=T x^{*}$.

We generalize the main result of Berinde [32] in the framework of partially ordered metric spaces.

Theorem 3 Let $(X, d, \preceq)$ be a partially ordered metric space which is complete. Assume that $T: X \rightarrow X$ is a continuous map satisfying $x \preceq T x \forall x \in X$, and let $T$ satisfy

$$
F(d(T x, T y), d(x, y), d(x, T x), d(y, T y), d(x, T y), d(y, T x)) \leq 0 \quad \text { for all } x \geq y,
$$

where $F \in \mathbb{F}_{2}$. Then

(p1) $\operatorname{Fix}(T) \neq \emptyset$;

(p2) for any $x_{0} \in X$, the Picard iteration $\left\{x_{n}\right\}_{n=0}^{\infty}$ converges to a fixed point $x^{*} \in X$ of $T$;

(p3) the following estimate holds:

$$
d\left(x_{n+i-1}, x^{*}\right) \leq \frac{k^{i}}{1-h} d\left(x_{n}, x_{n-1}\right), \quad n=0,1,2, \ldots, i=1,2, \ldots ;
$$

(p4) if additionally $F \in \mathbb{F}_{4}$, then the rate of convergence of the Picard iteration is given by

$$
d\left(x_{n+1}, x^{*}\right) \leq k d\left(x_{n}, x^{*}\right) .
$$

Proof Let $x_{0} \in X$ be arbitrary. Since $T$ is non-decreasing, we have $x_{0} \preceq T x_{0}$. We define a sequence $\left\{x_{n}\right\}$ in $X$ as follows:

$$
x_{n}=T x_{n-1} \quad \text { for } n \geq 1 \text {. }
$$

Considering that $T$ is a non-decreasing mapping together with (2.26), we have $x_{2}=T x_{1} \succeq$ $x_{1}$. Inductively, we obtain

$$
x_{0} \preceq x_{1} \preceq x_{2} \preceq \cdots \preceq x_{n-1} \preceq x_{n} \preceq x_{n+1} \preceq \cdots .
$$

Assume that there exists $n_{0}$ such that $x_{n_{0}}=x_{n_{0}+1}$. Since $x_{n_{0}}=x_{n_{0}+1}=T x_{n_{0}}$, then $T$ has a fixed point which ends the proof. Suppose that $x_{n} \neq x_{n+1}$ for all $n \in \mathbb{N}$. Thus, by (2.27), we have

$$
x_{0} \prec x_{1} \prec x_{2} \prec \cdots \prec x_{n-1} \prec x_{n} \prec x_{n+1} \prec \cdots
$$

Taking (2.25) into account, we derive that

$$
F\left(d\left(x_{n}, T x_{n}\right), d\left(x_{n-1}, x_{n}\right), d\left(x_{n-1}, x_{n}\right), d\left(x_{n}, x_{n+1}\right), d\left(x_{n-1}, x_{n+1}\right), 0\right) \leq 0 .
$$

By the triangle inequality, we have

$$
d\left(x_{n-1}, x_{n+1}\right) \leq d\left(x_{n}, x_{n+1}\right)+d\left(x_{n-1}, x_{n}\right) .
$$


Since $F$ is non-increasing in the fifth variable, the inequality (2.29) turns into

$$
F\left(d\left(x_{n}, T x_{n}\right), d\left(x_{n-1}, x_{n}\right), d\left(x_{n-1}, x_{n}\right), d\left(x_{n}, x_{n+1}\right), d\left(x_{n}, x_{n+1}\right)+d\left(x_{n-1}, x_{n}\right), 0\right) \leq 0,
$$

and by $\mathbb{F}_{2}$, we have $\exists k \in[0,1)$ such that

$$
d\left(x_{n}, x_{n+1}\right) \leq k d\left(x_{n}, x_{n-1}\right)
$$

which implies that $\left\{x_{n}\right\}_{n=0}^{\infty}$ is a Cauchy sequence. Since $X$ is a complete metric space, we have $\lim x_{n}=x^{*} \in X$. Since $T$ is continuous,

$$
x^{*}=\lim _{n \rightarrow \infty} x_{n+1}=\lim _{n \rightarrow \infty} T x_{n}=T\left(\lim _{n \rightarrow \infty} x_{n}\right)=T x^{*}
$$

and this proves ( $\mathrm{p} 1)$.

(p2): follows by the proof of (p1).

(p3): follows by equation (2.30).

(p4): Taking $x:=x_{n}$ and $y:=x^{*}$ in equation (2.25), we have

$$
F\left(d\left(x_{n+1}, T x^{*}\right), d\left(x_{n}, x^{*}\right), d\left(x_{n}, x_{n+1}\right), 0, d\left(x_{n}, T x^{*}\right), d\left(x^{*}, x_{n+1}\right)\right) \leq 0 .
$$

By the triangle inequality, we have $d\left(x_{n}, x_{n+1}\right) \leq d\left(x_{n}, x^{*}\right)+d\left(x^{*}, x_{n+1}\right)$, and hence by assumption $\mathbb{F}_{3}$, we have

$$
F\left(d\left(x_{n+1}, x^{*}\right), d\left(x_{n}, x^{*}\right), d\left(x_{n}, x^{*}\right)+d\left(x^{*}, x_{n+1}\right), 0, d\left(x_{n}, T x^{*}\right), d\left(x^{*}, x_{n+1}\right)\right) \leq 0 .
$$

Again, by assumption $\mathbb{F}_{3}$, this implies that $\exists k \in[0,1)$ such that $d\left(x_{n+1}, x^{*}\right) \leq k d\left(x_{n}, x^{*}\right)$.

Remark 4 Let $F_{1} \in \mathbb{F}$ such that $F_{1}\left(t_{1}, t_{2}, t_{3}, t_{4}, t_{5}, t_{6}\right)=t_{1}-k t_{2}$ where $k \in[0,1)$. If we take $F=F_{1}$ in Theorem 3, then we get the main result of Ran and Reurings (Theorem 2.1 of [16]).

We get the same results by removing the continuity condition of the mapping $T$ in Theorem 3 and by adding the condition that $X$ is regular.

Theorem 5 Let $(X, d, \preceq)$ be a partially ordered metric space which is complete and regular. Assume that $T: X \rightarrow X$ satisfies $x \preceq T x \forall x \in X$ and

$$
F(d(T x, T y), d(x, y), d(x, T x), d(y, T y), d(x, T y), d(y, T x)) \leq 0 \quad \text { for all } x \geq y,
$$

where $F \in \mathbb{F}_{2}$. Then

(p1) $\operatorname{Fix}(T) \neq \emptyset$;

(p2) for any $x_{0} \in X$, the Picard iteration $\left\{x_{n}\right\}_{n=0}^{\infty}$ converges to a fixed point $x^{*} \in X$ of $T$;

(p3) the following estimate holds:

$$
d\left(x_{n+i-1}, x^{*}\right) \leq \frac{k^{i}}{1-h} d\left(x_{n}, x_{n-1}\right), \quad n=0,1,2, \ldots, i=1,2, \ldots ;
$$


(p4) if additionally $F \in \mathbb{F}_{4}$, then the rate of convergence of the Picard iteration is given by

$$
d\left(x_{n+1}, x^{*}\right) \leq k d\left(x_{n}, x^{*}\right) .
$$

Proof Following the line in the proof of Theorem 3, we get a Cauchy sequence $\left\{x_{n}\right\}$ as it is defined above. Since $X$ is a complete metric space, we have $\lim x_{n}=x^{*} \in X$. Since $(X, d)$ is regular, we have $x^{*} \preceq x_{n} \forall n \in \mathbb{N}$. Hence, taking $x:=x_{n}$ and $y:=x^{*}$ in equation (2.31), we have

$$
F\left(d\left(T x_{n}, T x^{*}\right), d\left(x_{n}, x^{*}\right), d\left(x_{n}, T x_{n}\right), d\left(x^{*}, T x^{*}\right), d\left(x_{n}, T x^{*}\right), d\left(x^{*}, T x_{n}\right)\right) \leq 0
$$

for all $n \in \mathbb{N}$. Since $F$ is continuous, letting $n \rightarrow \infty$, we have

$$
F\left(d\left(x^{*}, T x^{*}\right), 0,0, d\left(x^{*}, T x^{*}\right), d\left(x^{*}, T x^{*}\right), 0\right) \leq 0 .
$$

Hence, by $\mathbb{F}_{2}$, we have $d\left(x^{*}, T x^{*}\right) \leq 0$, which implies that $x^{*}=T x^{*}$ and this proves (p1).

The rest of the proof is the same as the proof of Theorem 3 .

Remark 6 Let $F_{1} \in \mathbb{F}$ such that $F_{1}\left(t_{1}, t_{2}, t_{3}, t_{4}, t_{5}, t_{6}\right)=t_{1}-k t_{2}$ where $k \in[0,1)$. If we take $F=$ $F_{1}$ in Theorem 5, then we get the main result of Nieto and Rodríguez-López (Theorem 2.2 of [17]).

Remark 7 If we take $\phi(t)=k t$ in Theorem 1 (respectively, Theorem 2) where $k \in[0,1$ ) we get (p1) of Theorem 3 (respectively, Theorem 5).

\section{Uniqueness of a fixed point}

In this section, we investigate the uniqueness of fixed points in the theorems above. In order to assure the uniqueness of fixed points, we need the following notion on the partially ordered metric space $(X, \preceq)$ which is called the comparability condition:

(C) For every $x, y \in X$, there exists $z \in X$ such that either $x \preceq z$ and $y \preceq z$ or $z \preceq x$ and $z \preceq y$.

We also require the following condition:

$\left(\mathbb{F}_{6}\right) F \in \mathbb{F}$ is non-increasing in the fourth variable and such that $F(u, v, 0, u+v, u, v) \geq 0$ for all $u, v>0$.

Adding condition $(C)$ and $\mathbb{F}_{6}$ to the hypotheses of Theorem 1 , we obtain the uniqueness of the fixed point:

Theorem 8 Let $(X, d, \preceq)$ be a partially ordered metric space which is complete and which satisfies $(C)$. Assume that $T: X \rightarrow X$ is a continuous map satisfying $x \preceq T x \forall x \in X$, and let T satisfy

$$
F(d(T x, T y), d(x, y), d(x, T x), d(y, T y), d(x, T y), d(y, T x)) \leq 0 \quad \text { for all } x \geq y,
$$

where $F \in \mathbb{F}_{1} \cap \mathbb{F}_{5} \cap \mathbb{F}_{6}$. Then $T$ has a unique fixed point. 
Proof Due to Theorem 1, we guarantee that $T$ has a fixed point. Suppose $x$ and $y$ are fixed points of $T$ with $x \neq y$.

We need to examine two cases:

Case (i): If $x$ and $y$ are comparable, then

$$
F(d(T x, T y), d(x, y), d(x, T x), d(y, T y), d(x, T y), d(y, T x)) \leq 0 \quad \text { for all } x \geq y,
$$

which is equivalent to

$$
F(d(x, y), d(x, y), 0,0, d(x, y), d(x, y)) \leq 0,
$$

which contradicts $\mathbb{F}_{5}$. Hence $x=y$.

Case (ii): If $x$ and $y$ are not comparable, then by $(C)$ there exists $z$ such that $x \preceq z$ and $y \preceq z$. Then

$$
F(d(T x, T z), d(x, z), d(x, T x), d(z, T z), d(z, T x), d(x, T z)) \leq 0 \quad \text { for all } z \geq x,
$$

which is equivalent to

$$
F(d(x, T z), d(x, z), 0, d(z, T z), d(x, z), d(x, T z)) \leq 0 .
$$

By $\mathbb{F}_{6}, F$ is non-increasing in the fourth variable, and hence we have

$$
F(d(x, T z), d(x, z), 0, d(z, x)+d(x, T z), d(x, T z), d(z, x)) \leq 0,
$$

which contradicts $\mathbb{F}_{6}$. Hence, we have $x=y$.

Adding condition $(C)$ and $\mathbb{F}_{6}$ to the hypotheses of Theorem 2, we obtain the uniqueness of the fixed point.

Theorem 9 Let $(X, d, \preceq)$ be a partially ordered metric space which is complete and regular. Let $(X, d, \preceq)$ also satisfy condition $(C)$. Assume that $T: X \rightarrow X$ satisfies $x \preceq T x \forall x \in X$ and

$$
F(d(T x, T y), d(x, y), d(x, T x), d(y, T y), d(x, T y), d(y, T x)) \leq 0 \quad \text { for all } x \geq y,
$$

where $F \in \mathbb{F}_{1} \cap \mathbb{F}_{5} \cap \mathbb{F}_{6}$. Then $T$ has a unique fixed point.

Proof The proof is the same as the proof of Theorem 8.

Adding condition $(C)$ to the hypotheses of Theorem 3, we obtain the uniqueness of the fixed point:

Theorem 10 Let $(X, d, \preceq)$ be a partially ordered metric space which is complete. Let $(X, d, \preceq)$ also satisfy condition $(C)$. Assume that $T: X \rightarrow X$ is a continuous non-decreasing map, i.e., $x \preceq T x \forall x \in X$, and let $T$ satisfy

$$
F(d(T x, T y), d(x, y), d(x, T x), d(y, T y), d(x, T y), d(y, T x)) \leq 0 \quad \text { for all } x \geq y,
$$

where $F \in \mathbb{F}_{2} \cap \mathbb{F}_{6}$. Then 
(p1) Thas a unique fixed point;

(p2) for any $x_{0} \in X$, the Picard iteration $\left\{x_{n}\right\}_{n=0}^{\infty}$ converges to a fixed point $x^{*} \in X$ of $T$;

(p3) the following estimate holds:

$$
d\left(x_{n+i-1}, x^{*}\right) \leq \frac{k^{i}}{1-h} d\left(x_{n}, x_{n-1}\right), \quad n=0,1,2, \ldots, i=1,2, \ldots ;
$$

(p4) if additionally $F \in \mathbb{F}_{4}$, then the rate of convergence of the Picard iteration is given by

$$
d\left(x_{n+1}, x^{*}\right) \leq k d\left(x_{n}, x^{*}\right) .
$$

Proof The proof is the same as the proof of Theorem 8.

Adding condition $(C)$ and $\mathbb{F}_{6}$ to the hypotheses of Theorem 5 , we obtain the uniqueness of a fixed point:

Theorem 11 Let $(X, d, \preceq)$ be a partially ordered metric space which is complete and regular. Let $(X, d, \preceq)$ also satisfy condition $(C)$. Assume that $T: X \rightarrow X$ satisfies $x \preceq T x \forall x \in X$ and

$$
F(d(T x, T y), d(x, y), d(x, T x), d(y, T y), d(x, T y), d(y, T x)) \leq 0 \quad \text { for all } x \geq y,
$$

where $F \in \mathbb{F}_{2} \cap \mathbb{F}_{6}$. Then

(p1) $T$ has a unique fixed point;

(p2) for any $x_{0} \in X$, the Picard iteration $\left\{x_{n}\right\}_{n=0}^{\infty}$ converges to a fixed point $x^{*} \in X$ of $T$;

(p3) the following estimate holds:

$$
d\left(x_{n+i-1}, x^{*}\right) \leq \frac{k^{i}}{1-h} d\left(x_{n}, x_{n-1}\right), \quad n=0,1,2, \ldots, i=1,2, \ldots ;
$$

(p4) if additionally $F \in \mathbb{F}_{4}$ then the rate of convergence of the Picard iteration is given by

$$
d\left(x_{n+1}, x^{*}\right) \leq k d\left(x_{n}, x^{*}\right) .
$$

Proof The proof is the same as the proof of Theorem 8.

\section{Competing interests}

The authors declare that they have no competing interests.

Authors' contributions

Both authors contributed equally to the paper.

\section{Author details}

${ }^{1}$ Department of Mathematics, Hacettepe University, Ankara, Turkey. ${ }^{2}$ Department of Mathematics, Atilim University, incek, Ankara 06836, Turkey.

\section{Acknowledgements}

The authors would like to thank the referees for their valuable suggestions on improving the text. 


\section{References}

1. Cherichi, M, Samet, B: Fixed point theorems on ordered gauge spaces with applications to nonlinear integral equations. Fixed Point Theory Appl. 2012, 13 (2012)

2. Banach, S: Sur les operations dans les ensembles abstraits et leur application aux equations integrales. Fundam. Math. 3, 133-181 (1922)

3. Hardy, GC, Rogers, T: A generalization of fixed point theorem of Reich. Can. Math. Bull. 16, 201-206 (1973)

4. Kannan, R: Some results on fixed points - II. Am. Math. Mon. 76, 71-76 (1969)

5. Reich, S: Some remarks concerning contraction mappings. Can. Math. Bull. 14, 121-124 (1971)

6. Chu, SC, Diaz, JB: Remarks on a generalization of Banach's mappings. J. Math. Anal. Appl. 11, 440-446 (1965)

7. Bonsall, FF: Lectures on Some Fixed Point Theorems of Functional Analysis. Tata Institute of Fundamental Research, Bombay (1962)

8. Smart, DR: Fixed Point Theorems. Cambridge University Press, Cambridge (1974)

9. Sehgal, VM: A fixed point theorem for mappings with a contractive iterate. Proc. Am. Math. Soc. 23, 631-634 (1969)

10. Reich, S: Kannan's fixed point theorem. Boll. Unione Mat. Ital. 4, 1-11 (1971)

11. Edelstein, M: On fixed points and periodic points under contraction mappings. J. Lond. Math. Soc. 37, 74-79 (1962)

12. Holmes, RD: On fixed and periodic points under sets of mappings. Can. Math. Bull. 12, 813-822 (1969)

13. Nadler, SB Jr.: Sequences of contractions and fixed points. Pac. J. Math. 27, 579-585 (1968)

14. Wong, CS: Common fixed points of two mappings. Pac. J. Math. 48, 299-312 (1973)

15. Samet, B: Coupled fixed point theorems for a generalized Meir-Keeler contraction in partially ordered metric spaces Nonlinear Anal. 72, 4508-4517 (2010)

16. Ran, ACM, Reurings, MCB: A fixed point theorem in partially ordered sets and some applications to matrix equations. Proc. Am. Math. Soc. 132, 1435-1443 (2004)

17. Nieto, JJ, Rodríguez-López, R: Contractive mapping theorems in partially ordered sets and applications to ordinary differential equations. Order 22(3), 223-239 (2005)

18. Alber, Yl, Guerre-Delabriere, S: Principle of weakly contractive maps in Hilbert space. In: Gohberg, I, Lyubich, Y (eds.) New Results in Operator Theory, Advances and Its Applications, vol. 98, pp. 7-22. Birkhäuser, Basel (1997)

19. Boyd, DW, Wong, SW: On nonlinear contractions. Proc. Am. Math. Soc. 20, 458-464 (1969)

20. Karapınar, E: Fixed point theory for cyclic weak $\phi$-contraction. Appl. Math. Lett. 24, 822-825 (2011)

21. Kirk, WA, Srinavasan, PS, Veeramani, P: Fixed points for mapping satisfying cyclical contractive conditions. Fixed Point Theory 4, 79-89 (2003)

22. Petruşel, G: Cyclic representations and periodic points. Stud. Univ. Babeş-Bolyai, Math. L(3), 107-112 (2005)

23. Rus, IA: Cyclic representations and fixed points. Ann. T. Popoviciu Semin. Funct. Equ. Approx. Convexity 3, 171-178 (2005)

24. Rhoades, BE: Some theorems on weakly contractive maps. Nonlinear Anal. 47(4), 2683-2693 (2001)

25. Păcurar, M, Rus, IA: Fixed point theory for cyclic $\varphi$-contractions. Nonlinear Anal. 72(3-4), 1181-1187 (2010)

26. Hussain, N, Jungck, G: Common fixed point and invariant approximation results for noncommuting generalized $(f, g)$-nonexpansive maps. J. Math. Anal. Appl. 321, 851-861 (2006)

27. Song, Y: Coincidence points for noncommuting $f$-weakly contractive mappings. Int. J. Comput. Appl. Math. 2(1), 51-57 (2007)

28. Song, Y, Xu, S: A note on common fixed-points for Banach operator pairs. Int. J. Contemp. Math. Sci. 2, 1163-1166 (2007)

29. Zhang, Q, Song, Y: Fixed point theory for generalized $\varphi$-weak contractions. Appl. Math. Lett. 22(1), 75-78 (2009)

30. Abdeljawad, T, Karapınar, E: Quasi-cone metric spaces and generalizations of Caristi Kirk's theorem. Fixed Point Theory Appl. (2009). doi:10.1155/2009/574387

31. Berinde, V: Contractii generalizate si aplicatii, vol. 22. Editura Cub Press, Baia Mare (2007)

32. Berinde, V: Approximating fixed point of almost contractions. Hacet. J. Math. Stat. 41(1), 93-102 (2012)

doi:10.1186/1029-242X-2012-217

Cite this article as: Gül and Karapınar: On almost contractions in partially ordered metric spaces via implicit relations. Journal of Inequalities and Applications 2012 2012:217.

\section{Submit your manuscript to a SpringerOpen ${ }^{0}$ journal and benefit from:}

- Convenient online submission

- Rigorous peer review

- Immediate publication on acceptance

- Open access: articles freely available online

- High visibility within the field

- Retaining the copyright to your article 